\title{
POTENSI TEKANAN WATER HAMMER PADA PIPA PVC 1,5 IN SEBAGAI DRIVE PIPE UNTUK POMPA HIDRAM
}

\author{
Rusmana $^{1}$, Salsabila Risti Runisa ${ }^{2}$ Rima Melati ${ }^{3}$ \\ Jusrusan Teknik Konversi Energi Politeknik Negeri Bandung \\ e-mail : rimaaamel@gmail.com
}

\begin{abstract}
ABSTRAK
Pada penelitian ini dibuat simulasi sistem pompa hidram yang mencakup instalasi pengujian water hammer dengan tambahan drive pipe berbahan PVC dan Galvanis. Pipa uji terdiri dari pipa galvanis diameter $I$ in sepanjang 25 meter dan disambung dengan pipa galvanis diameter 1,5 in sepanjang 12,25 meter. Pipa uji byang ke 2 adalah pipa galvanis diameter 1 in disambung dengan pipa PVC diameter 1,5 in sepanjang 12,25 meter. Simulasi ini bertujuan untuk melihat fenomena potensi tekanan water hammer pada kedua pipa uji tersebut. Sumber air dialirkan dengan menggunakan pompa ke pipa uji sebagai drive pipe lalu aliran tersebut dihentikan oleh penutupan katup solenoid yang diatur oleh ATMEGA 16 controller. Tekanan yang dihasilkan akibat penutupan katup inilah yang disebut tekanan water hammer yang kemudian disimpan di air chamber. Jika katup delivery dibuka maka air mengalir melalui delivery pipe. Semakin tinggi tekanan water hammer maka semakin tinggi kemampuan untuk menaikan air. Pemilihan material untuk bahan drive pipe.akan berpengaruh pada tekanan yang dihasikan. Penggunaan pipa PVC pada debit 202,75 ml/s menghasilkan tekanan sebesar 4 bar. Sedangkan pipa galvanis pada debit 185,12 ml/s menghasilkan tekanan sebesar 4,7 bar.
\end{abstract}

Kata kunci: Water hammer, Drive pipe, Delivery pipe, PVC Pipe, Galvanis pipe

\section{PENDAHULUAN}

Air mengalir dari tempat yang tinggi ke tempat yang rendah. Air yang mengalir tersebut memiliki energy kinetic yang cukup besar. Pada penelitian ini akan di bahas tentang konversi energy kinetic menjadi energy tekanan. Sehingga energy tekanan tersebut dapat dimanfaatkan untuk memindahkan air dari tempat yang rendah ke tempat yang lebih tinggi. Pemanfaatan tekanan water hammer dapat diaplikasikan pada sebuah pompa hydram.

Hydram (hydraulic ram) merupakan suatu alat yang digunakan untuk menaikkan air dari tempat rendah ke tempat yang lebih tinggi secara otomatis dengan energi yang berasal dari air itu sendiri [1].

Dengan berbekal pengetahuan dan teknologi yang dikuasai maka dengan phenomena tersebut dapat dibuat sebuah alat yaitu pompa hydraulic ram Pompa ini tidak menggunakan motor listrik atau sumber listrik sebagai penggeraknya. Sehingga pompa ini menjadi pilihan untuk penghematan energy dan tepat digunakan di pedesaan yang tidak mendapat pasokan listrik .

Material yang digunakan akan berpengaruh pada tekanan water hamer, seperti kurva yang ditunjukan oleh Mitosek et al, 1998 [2].

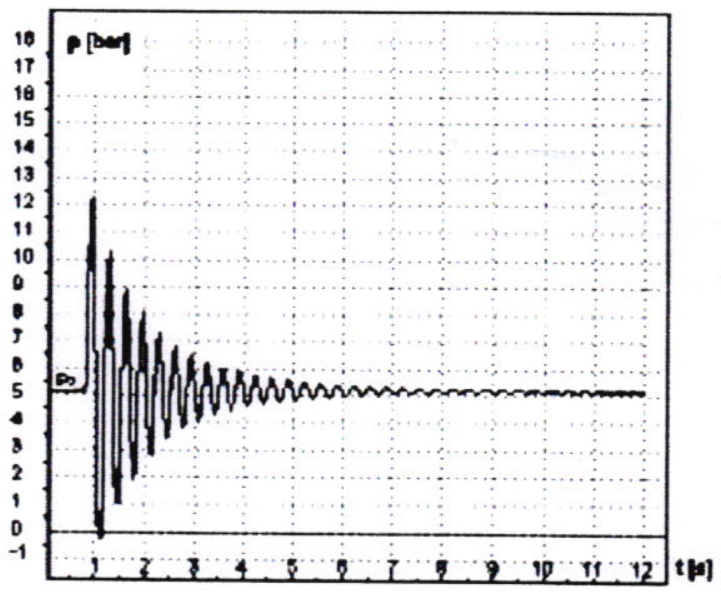

(a)

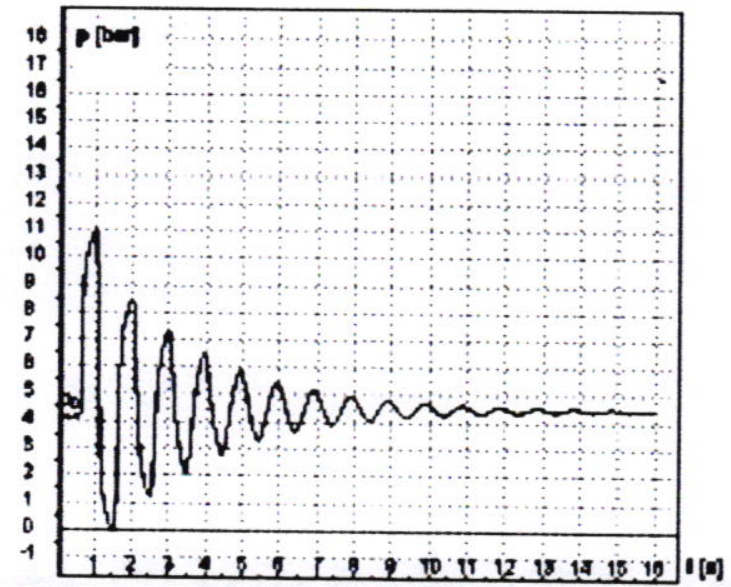

(b) 
Gambar 1. (a) Kurva gelombang tekanan water hammer pada pipa besi (b) Kurva gelombang tekanan water hammer pada pipa PVC [2]

Demikian halnya dengan pembukaan dan penutupan katup aliran dapat menimbulkan gelombang tekanan water hammer yang bergerak menuju ke arah sumber dan tekanan yang ditimbulkan lebih tinggi dari tekanan maksimum pompa. [3].

Tekanan puncak pada fenomena water hammer akibat penutupan katup dipengaruhi oleh karakteristik katup tak berdimensi yang terbentuk dari waktu penutupan, pola gerakan dan karakteristik katupnya sehingga dengan karakteristik katup dan pola penutupan yang konstan serta lambat akan cenderung memberikan puncak kenaikan yang lebih rendah [4].

Tekanan yang terjadi dipengaruhi oleh adanya peristiwa water hammer sepanjang pipa. Maka dari itu untuk mengetahui besarnya tekanan yang dibangkitkan akan berkaitan dengan peristiwa water hammer.

\section{TINJAUAN PUSTAKA}

Persamaan gelombang satu dimensi untuk menjelaskan efek water hammer dibuat oleh Joukowsky pada tahun 1898. Berikut ini merupakan persamaan Joukowsky [5].

$\Delta P=\rho c \Delta V$

$\Delta \mathrm{P}=$ Tekanan akibat water hammer $\left(\mathrm{N} / \mathrm{m}^{2}\right)$

$c=$ kecepatan gelombang tekanan $(\mathrm{m} / \mathrm{s})$

$\Delta \mathrm{V}=$ perubahan kecepatan fluida di saluran $(\mathrm{m} / \mathrm{s})$

$\rho=$ massa jenis fluida $\left(\mathrm{kg} / \mathrm{m}^{3}\right)=1000$

$\left(\mathrm{kg} / \mathrm{m}^{3}\right)$ Persamaan tersebut dapat juga ditulis sebagai berikut.

$\Delta H=\frac{c \Delta V}{g}$

$\Delta \mathrm{H}=$ kenaikan tekanan pada water hammer $\left(\mathrm{N} / \mathrm{m}^{2}\right)$

$c=$ kecepatan gelombang tekanan $(\mathrm{m} / \mathrm{s})$

$\mathrm{g}=$ percepatan gravitasi $\left(\mathrm{N} / \mathrm{m}^{2}\right)=9.81\left(\mathrm{~m} / \mathrm{s}^{2}\right)$

Kecepatan gelombang tekanan (c) merupakan fungsi dari beberapa parameter, seperti berat spesifik, modulus elastisitas fluida, diameter pipa, ketebalan dinding pipa, modulus elastisitas pipa, dan panjang saluran. Berikut ini merupakan persamaan yang digunakan untuk menghitung kecepatan gelombang tekanan.

$$
\begin{aligned}
& c=\sqrt{\left.\frac{K}{1+\frac{D K}{E e}} \times \frac{1}{\rho} \ldots \ldots \ldots \ldots . . . . . . . .3\right)} \\
& \mathrm{D}=\operatorname{diameter} \text { pipa (m) } \\
& \mathrm{e}=\text { ketebalan dinding pipa (m) } \\
& \mathrm{E}=\text { modulus elastisitas pipa } \\
& \mathrm{K}=\text { modulus elastisitas fluida (air) }
\end{aligned}
$$

Proses pengujian yang akan dilakukan yaitu :

1. Kecepatan air dilakukan dengan menggunakan pompa yaitu dengan mengatur debit agar sesuai dengan yang dikehendaki. Pengaturan debit dilakukan dengan mengatur bukaan katup pembagi.

2. Mengatur periode bukaan katup melalui rangkaian kontrol agar diketahui peristiwa water hammer pada kondisi bukaan katup tersebut.

3. Pengujian awal dilakukan dengan drive pipe berbahan galvanis dengan diameter 1" sepanjang 25 meter.

4. Pengujian pipa uji PVC dilakukan dengan menambahkan pipa PVC dengan diameter 1,5 " sebagai drive pipe, sehingga drive pipe yang digunakan sepanjang 37 meter.

5. Pengujian dua dilakukan seperti langkah 4 dengan mengganti pipa PVC 1,5 dengan pipa Galvanis 1,5 in.

Beberapa parameter yang diukur dalam pengujian ini diantaranya adalah:

1. Tekanan Air

1) Tekanan air pada saluran discharge pompa.

2) Tekanan air masuk drive pipe.

3) Tekanan air masuk tangki udara.

4) Tekanan air di dekat solenoid valve.

2. Debit air

1) Debit air keluaran katup limbah.

2) Debit air keluaran delivery pipe.

3) Debit air sebelum terjadi water hammer.

Dari parameter-parameter tersebut dapat dilakukan perhitungan untuk mengetahui hasil simulasi pompa hidram yang telah dibuat, diantaranya:

1) Menghitung kenaikan tekanan pada pompa hidram 
Untuk menghitung kenaikan tekanan fluida yang terjadi pada pompa hidram, dapat dilakukan dengan cara membandingkan selisih antara tekanan pada sumber (P2) dengan tekanan pada air chamber $(P w)$.

$\Delta P=P_{1:}-P_{z}$

\section{METODE PENGUJIAN}

\section{Rancangan Instalasi Pengujian}

Istalasi pengujian tekanan water hammer terdiri dari tiga bagiab utama. Yang pertama yaitu instalasi sumber aliran fluida yang terdiri dari tangki air, pompa, alat ukur tekanan dan tabung tekanan.

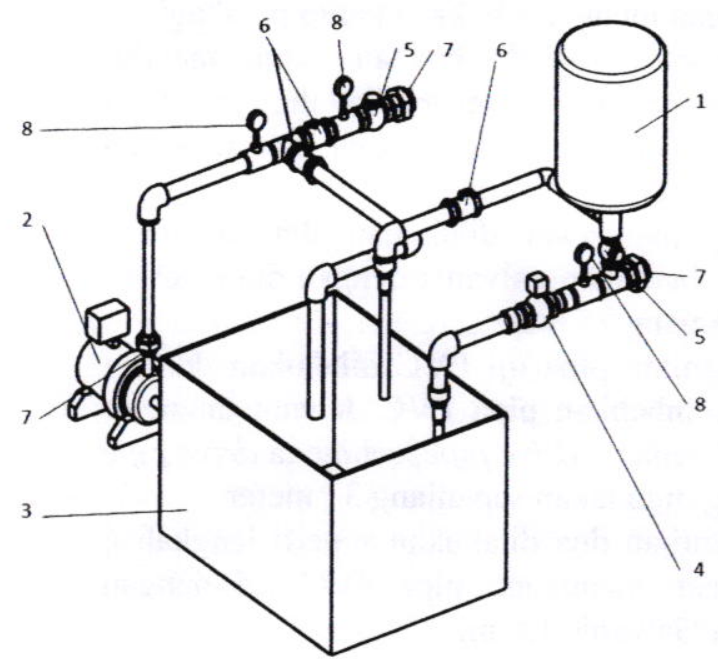

Gambar.1. Instalasi sumber aliran.

Keterangan:

$$
\begin{array}{ll}
1 & =\text { Air chamber } \\
2 & =\text { Pompa simulator head } \\
3 & =\text { Tangki air } \\
4 & =\text { Katup solenoid } \\
5 & =\text { Katupsatuarah } \\
6 & =\text { Katup bola } \\
7 & =\text { Water mur } \\
8 & =\text { Pressure gauge }
\end{array}
$$

Pipa uji terdiri dari pipa galvanis diameter 1 in sepanjang 25 meter ( pipa uji 1)dan disambung dengan pipa uji galvanis diameter 1,5 in sepajang 12,25 meter ( Pipa uji 2 ). Pipa uji galvanis 1,5 in akan diganti oleh pipa uji PVC diameter 1,5 dengan panjang 12,25 meter ( pipa uji 3). Gambar insatalasi pipa uji dijelaskan pada Gambar 2 di bawah.

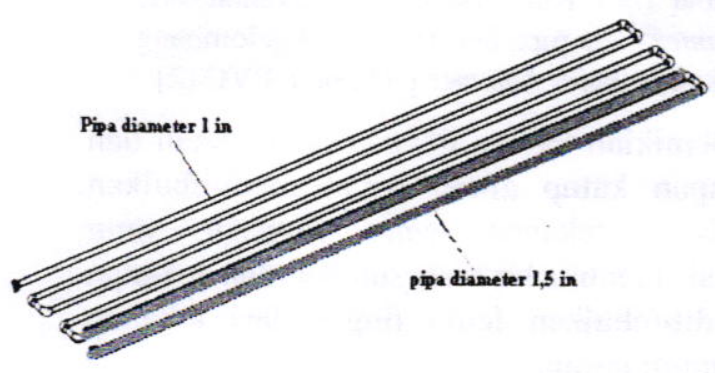

Gambar.2 Susunan Pipa uji.

Pipa uji akan disambungkan ke inastalasi sumber aliran dengan menggunakan water mur.

\section{Langkah Pengujian}

Pengujian dilakukan dengan 3 kali pengujian yaitu pengujian pipa uji 1, dilanjutkan dengan pipa uji 2 dan berikutnya dengan pipa uji 3 .

Langkah pengujian pipa uji satu adalah :

1. Pipa uji 1 dipasang pada instalasi sumber aliran

2. Buka katup aliran

3. Tutup katup bypass

4. Hidupkan controller AT Mega 16

5. Hidupkan pompa

6. Biarkan air mengalir sampai udara di dalam pipa uji keluar semua.

7. Aktifkat kontroler AT mega 16 agar membuka dan menutup katup solenoid.

8. Catat tekanan pada pressure gauge pipa uji (no.8 pada Gambar 1).

Langkah pengujian pipa uji dua.

1. Matikan pompa air agar aliran air berhenti,

2. Pasang /sambungkan pipa uji 2 ke pipa uji satu,

3. Hubungkan ujung pipa uji 2 menggunakan water mur 7 ,

4. Lakukan langkah 2 sd 8 pada langkah uji pipa1.

Langkah pengujian pipa uji tiga.

1. Matikan pompa air,

2. Lepaskan pipa uji 2 dari pipa uji satu dan water mur 7 ,

3. Ganti pipa uji dua tersebut dengan pipa uji tiga,

4. Pasang pipa uji tiga ke water mur no.7,

5. Lakukan langkah 2 sd 8 pada langkah penguian pipa satu. 


\section{HASIL DAN PEMBAHASAN}

Hasil pengujian tekanan akibat water hammer yang telah dilakukan menggunakan simulasi pompa sebagai penghasil aliran ditunjukan pada Tabel.1.

Tabel 1. Data hasil pengujian gabungan.

\begin{tabular}{|c|c|c|c|c|c|}
\hline \multicolumn{6}{|c|}{ Data hasil pengujian } \\
\hline \multicolumn{2}{|c|}{ pipa uji 1 } & \multicolumn{2}{|c|}{ Pipa uji 2 } & \multicolumn{2}{c|}{ Pipa uji 3 } \\
\hline pw & Qw & pwi & Qw & PW & QW \\
\hline bar & $\mathrm{ml} / \mathrm{s}$ & bar & $\mathrm{ml} / \mathrm{s}$ & bar & $\mathrm{ml} / \mathrm{s}$ \\
\hline 0.8 & 113.51 & 2.1 & 91.36 & 1.8 & 102.42 \\
\hline 1 & 120.19 & 2.2 & 117.85 & 2 & 126.23 \\
\hline 1.4 & 121.34 & 2.6 & 135.4 & 2.6 & 172.03 \\
\hline 1.6 & 138.12 & 3.2 & 152.38 & 2.8 & 176.46 \\
\hline 2.2 & 162.6 & 3.2 & 153.16 & 2.9 & 184.75 \\
\hline 2.4 & 167.37 & 3.6 & 154.02 & 3 & 188.46 \\
\hline 3.9 & 187.97 & 3.7 & 162.64 & 3.6 & 189.72 \\
\hline & & 4.5 & 180.26 & 4 & 202.75 \\
\hline & & 4.7 & 185.12 & & \\
\hline
\end{tabular}

Keterangan :

$\mathrm{P}_{\mathrm{w}} \quad=$ Tekanan tekanan water hammer (bar gauge)

$\mathrm{Q}_{\mathrm{w}} \quad=$ Debit air keluaran katup limbah (ml/detik)

Pada pengujian pipa satu terlihat debit bertambah maka tekanan water hammer yang dihasilkanpun meningkat.

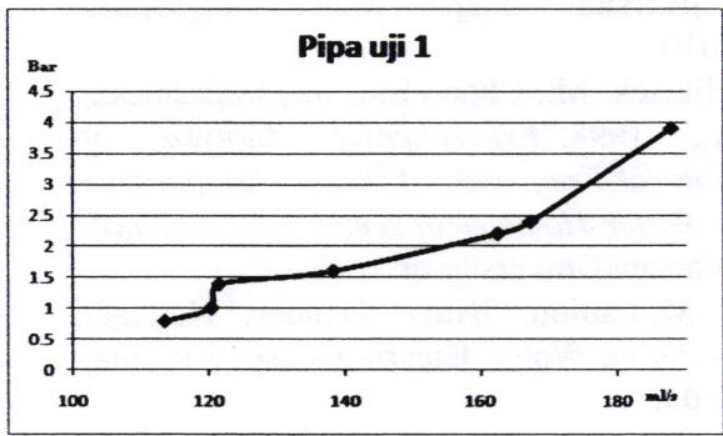

Gambar.3 Kurva hasil pengujian pipa uji satu.

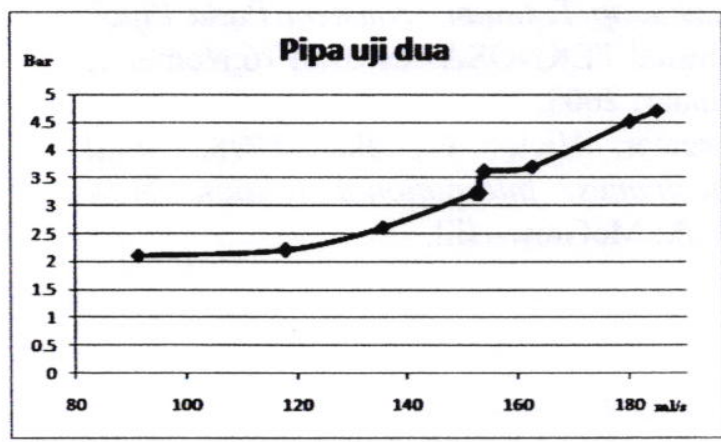

Gambar. 4 kurva pengujian pipa uji dua
Pada pipa uji dua tekanan yang dihasilkan mulai dari 2,1 bar dengan laju aliran 91,36 $\mathrm{ml} / \mathrm{s}$. Tekanan tertinggi yang dapat dihasilkan sebesar 4,7 bar dengan laju aliran sebesar $185,12 \mathrm{ml} / \mathrm{s}$. seperti pada kurva pengujian pipa dua

Pada pengujian pipa uji tiga tekanan yang dihasilkan mulai dari 1,8 bar akibat dari laju aliran 102,42 ml/s. Tekanan yang terbesar yang dapat dihasilkan sebesar 4 bar akibat dari laju aliran fluida sebesar $202,75 \mathrm{ml} / \mathrm{s}$

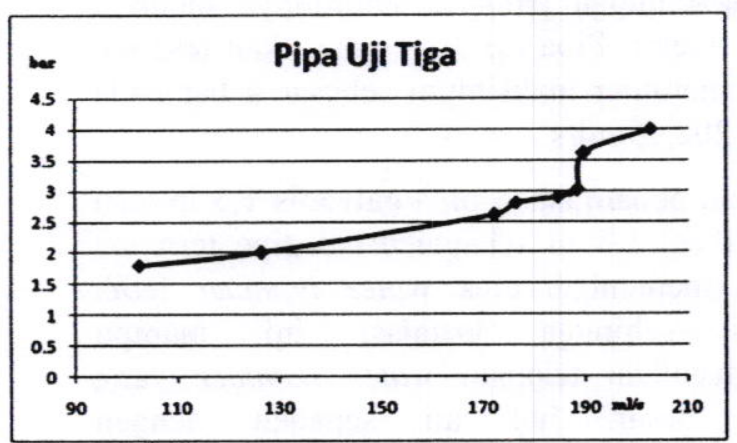

Gambar.4 Kurva hasil pengujian pipa uji tiga

Dari ketiga pengujian dapat diartikan bahwa per meter pipa dari masing masing pipa akan memberikan tekanan seperti tampak pada Tabel 2.

Tabel 2. Tekanan yang ditimbulkan /meter panjang pipa.

\begin{tabular}{|c|c|c|}
\hline $\begin{array}{c}\text { Jenis } \\
\text { Pipa }\end{array}$ & $\begin{array}{c}\text { Tekanan } \\
\text { bar/m }\end{array}$ & $\begin{array}{c}\text { Debit } \\
\mathrm{ml} / \mathrm{s}\end{array}$ \\
\hline pipa 1 & 0.156 & 187.97 \\
\hline Pipa 2 & 0.384 & 185.12 \\
\hline Pipa 3 & 0.327 & 202.75 \\
\hline
\end{tabular}

\section{Keterangan :}

Tekanan water hammer pw yang dihasilkan dari debit Qw dari masing masing pipa uji dapat dilihat pada Tabel.4. Besarnya tekanan yang muncul akibat dari penutupan katup yang tiba-tiba sangat dipengaruhi oleh debit. Pada penampang pipa yang sama kecepatan air dapat berubah akibat dari perubahan debit. Debit semakin besar maka kecepatan aliran fluida semakin cepat, hal ini sama dengan energy kinetiknya meningkat.

Pipa uji 1 adalah pipa berdiameter 1 in dengan panjang 25 meter, menghasilkan tekanan water 
hammer sebesar 3,9 bar pada saat debitnya $187,9 \mathrm{ml} / \mathrm{s}$.

Pipa uji 2 yaitu pipa uji 1 kemudian disambung dengan pipa galvanis diameter 1,5 in sepanjang 12 meter sehingga panjang pipa uji 2 adalah 37 meter. Pipa uji 2 menghasilkan tekanan water hammer maksimum sebesar 4,7 bar pada saat debitnya $185,12 \mathrm{ml} / \mathrm{s}$.

Pipa uji 3 adalah pipa uji 1 yang disambung dengan pipa PVC berdiameter 1,5 in sepanjang 12,25 sehingga panjang seluruhnya menjadi 37,25 meter. Pipa uji 3 menghasilkan tekanan water hammer maksimum sebesar 4 bar pada debit $202,75 \mathrm{ml} / \mathrm{s}$.

Dengan penambahan pipa galvanis 1,5 in atau pipa PVC 1,5 in sebagai drive pipe ternyata dapat menambah efek water hammer lebih tinggi sehingga instalasi ini mampu menghasilkan tekanan water hammer yang lebih besar, hal ini sepadan dengan kemampuannya untuk menaikkan air ke tempat yang lebih tinggi dan dengan debit yang dihasilkanpun lebih banyak sehingga membuat instalasi ini lebih baik.

Jika kita gabungkan hasil pengujian pipa satu, pipa dua dan pipa tiga maka akan terlihat lebih jelas perbedaan yang terjadi pada masingmasing pipa uji seperti terlihat pada Gambar 5.

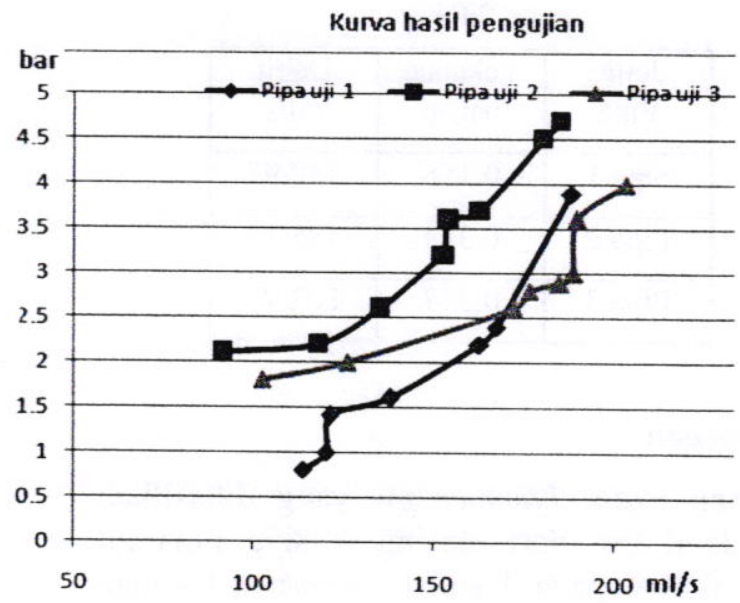

Gambar 5. Gabungan kurva hasil pengujian

Gambar 5. di atas menunjukkan pengaruh variasi debit sumber terhadap tekanan water hammer yang dihasilkan oleh sebuah model hidram yang mana semakin besar debit yang dialirkan ke dalam sistem hidram akan menghasilkan tekanan water hammer yang lebih besar pula.

\section{KESIMPULAN}

Setelah dilakukan proses pembuatan, pengujian serta pembahasan instalasi pengujian water hammer ini maka dapat disimpulkan bahwa :

1. Simulasi sistem pompa hidram dengan penambahan drive pipe berbahan PVC 1,5 ” yang telah dibuat dapat menghasilkan tekanan water hammer maksimal sebesar 4 bar.

2. Semakin tinggi tekanan water hammer yang dihasilkan maka semakin tinggi pula kemampuan pompa hidram untuk menaikkan air ke tempat yang lebih tinggi.

3. Fenomena tekanan water hammer dipengaruhi oleh debit air yang masuk melalui drive pipe dan panjang saluran drive pipe.

\section{DAFTAR PUSTAKA}

[1] Ahmad Nur Arianta, "Pengaruh Variasi Ukuran Tabung Udara Terhadap Unjuk Kerja Sebuah Pompa Hidram", Skripsi, Program Studi Teknik Mesin Jurusan Teknik Mesin Fakultas Teknik Universitas Gadjah Mada Yogyakarta 2010

[2] Mitosek, M., Chorzelski, M., Malesinska, A., 1998,"Experimental Analysis of Natural Frequency of Water Column Due to Water Hammer in series pipe Systems" Warsaw University of Technology.

[3] Z. M. Lahlou, "Water Hammer," National Drinking Water. Clearinghouse, Virginia, 2003.

[4] Sugati, D., Indarto., Purnomo., 2003, "Pengaruh Waktu Penutupan Katup Terhadap Tekanan Transient Pada Pipa" , Jurnal TEKNOSAINS, Jilid 16,Nomer 1, Januari 2003.

[5] Streeter, Victor L., dkk. 1998. Fluid Mechanics. International Edition. New York: McGraw-Hill. 